\title{
Entrepreneurial judgment as empathic accuracy: a sequential decision-making approach to entrepreneurial action
}

\author{
JEFFERY S. MCMULLEN* \\ Kelley School of Business, Indiana University, 1309 East Tenth Street, Bloomington, IN 47405-1701, USA
}

\begin{abstract}
Entrepreurship theory within economics has long touted the importance of judgment in entrepreneurial action. More recently, proponents have begun to advocate extension of this work to organization studies. However, critics of entrepreneurial judgment have responded by claiming that the construct is only meaningful post hoc and vapid when examined ex ante. Instead, they claim that, if entrepreneurship theory is to progress, then judgment must be replaced by a process logic known as effectuation. This article examines their claims and redefines the judgment dilemma as one of scope rather than existence. Empathic accuracy is then introduced to offer a means of addressing their criticism without having to deny the existence of entrepreneurial judgment. Empathic accuracy is also shown to be capable of explaining some of the cognitive mechanisms necessary for effectuation and dynamic socio-economic order.
\end{abstract}

There is growing interest in entrepreneurial judgment within the management literature. Recently, the construct has been used to analyze opportunity identification and evaluation (McMullen and Shepherd, 2006), entrepreneurial projects (Casson and Wadeson, 2007), and the theory of the firm (Casson, 1982; Foss and Klein, 2008, 2012). However, entrepreneurial judgment has also drawn the critical ire of effectuation researchers who have equated it with clairvoyance and claimed that it is 'rather unrealistic - a matter of hand-waving then thoughtful theorizing or careful observation' (Sarasvathy and Dew, 2013: 284). Defining judgment as 'the ex-ante ability to make decisions that turn out to be correct ex-post', Sarasvathy and Dew (2013: 285), for example, argue that the construct pushes scholars into tautological corners, from which they must explain 'good projects' in terms of 'good judgment' (e.g., Casson and Wadeson, 2007) or the 'heterogeneity of capital' in terms of the heterogeneity of an ability that is an 'unfathomable mystery of life and mind' (Knight, 1921).

The purpose of this article is to offer a defense of entrepreneurial judgment in a more modest manifestation known as empathic accuracy. Building on the judgment and decision-making literature from cognitive psychology, I show

*Email: mcmullej@indiana.edu 
that judgment is the operant between an opportunity belief (stimulus) and an investment (response). Using the S-O-R (stimulus-operant-response) elements, research in the psychology of Judgment and Decision Making (JDM) has built a rigorous decision-making framework capable of analyzing both economic and behavioral theories of entrepreneurship. Whereas economic theories of entrepreneurship tend to collapse the entrepreneurial journey into a single moment of time at which judgment is exercised to anticipate accurately or inaccurately the outcome associated with goal pursuit (Dimov, 2007), behavioral theories often argue that the entrepreneurial journey is a sequence of decisions about relatively simple events that culminate in the form of a complex event outcome (Dimov, 2011; McMullen and Dimov, 2013; Sarasvathy, 2001). By viewing entrepreneurial action as a process of sequential decision making, this article clarifies a number of miscommunications and reveals some interesting streams for future research.

First, Sarasvathy and Dew (2013) argue that the notion of entrepreneurial judgment should be replaced with effectual logic, which they argue is non-teleological and therefore not subject to futile attempts to predict the outcome of a complex event. Consistent with their criticism, I concede that economic theory on the topic has often presented an oversimplified, linear, and deterministic conception of entrepreneurial action. That concession, however, makes entrepreneurial judgment neither 'tautological' nor an 'unfathomable mystery', nor does it imply that effectuation negates the existence or usefulness of the entrepreneurial judgment construct. Indeed, Sarasvathy and Dew's (2013) critique rests on an understanding of entrepreneurial action as the culmination of an entrepreneurial process involving numerous interactions and transactions with various stakeholders. Because each of these transactions involves a new exchange with another party, empathic accuracy (as opposed to clairvoyance) is needed for entrepreneurial action to progress from desire to idea to viable product offering (Chiles et al., 2010; McMullen and Dimov, 2013). This empathic accuracy is facilitated by good judgment which requires mental models that accurately assess, estimate, or infer others' preferences well enough to form expectations of how various stakeholders will respond to the entrepreneur's new customer value proposition (McMullen, 2010). These models are informed by experiences with others, shared institutions, shared resources, social skill, empathic imagination, and other sources. Thus, viewing entrepreneurial action as sequential decision making as opposed to a one-time shot requires a reconceptualization of the nature of entrepreneurial judgment. Instead of judgment being the ability to predict accurately the outcome of a complex event, the judgment construct is relegated to the more mundane, but still difficult, task of achieving empathic accuracy, which involves social inference in predicting potential stakeholders' preferences sufficiently enough to gauge the nature and magnitude of their interest in the entrepreneur's offer. 
Second, despite convergence in the entrepreneurship literature about the nature of the entrepreneurial response as an investment of one's time, talent, or treasure, in the form of a decision or commitment to act (Dew et al., 2009; Foss and Klein, 2012; Mullins and Forlani, 2005; Shepherd et al., 2007), dissension remains concerning the nature of the stimulus that is being judged, or target of the decision being made. Foss and Klein (2012: 35) have even gone so far as to argue that no stimulus is needed. They suggest that 'opportunities' be replaced with the more parsimonious concept of 'investments' when theorizing about entrepreneurship, but this leaves the target of the decision unidentified. Individuals invest in something - an idea, a goal, a course of action, etc. The circumscribed version of entrepreneurial judgment offered in this article not only acknowledges this need for a target but also sheds light on its nature. If entrepreneurial action is the result of decisions either to invest or continue investing one's time, talent, and treasure in a course of action, then investment is the response to a decision made under uncertainty about whether there is demand for the entrepreneur's offering (or some possible variant of it) (Autio et al., 2013; McMullen, 2010) as well as about whether the entrepreneur and other stakeholders are both willing and able to produce such an offering given the expected price that potential customers are willing to pay (McMullen, 2011).

Viewing entrepreneurial action through the lens of sequential decision making suggests that there are micro-decisions nested within the hierarchy of a macrodecision. Economic theories of entrepreneurial action tend to focus on the macro-decision to initiate entrepreneurial action (at Time 0 ) and the outcome of that macro-decision (at Time 10) while neglecting the micro-decisions involved in the judgment to persist, abandon, or re-direct the entrepreneurial journey given environmental feedback during the time transpiring between initiation and conclusion (Times 1-9). This can make the outcome of action appear to have been inevitable or predetermined when viewed in retrospect, such that the time lapsing between initiation and conclusion is nothing more than noise (McMullen and Dimov, 2013) when in reality each of these micro-decisions required an opportunity belief and the need for judgment, often in the form of empathic accuracy. In turn, micro-decisions of whether and how to continue investing shape the ultimate outcome. To date, the entrepreneurship literature in management or economics have yet to make a distinction between the macrodecision of entrepreneurial action and the micro-decisions that comprise it. As discussed in this article, however, this distinction affects how opportunity is conceived and studied and may have significant implications for decision-making phenomena such as escalation of commitment or mission drift.

The remainder of this paper proceeds as follows. After building on psychology's judgment and decision-making (JDM) literature to define judgment, I explain why, contrary to arguments by Foss and Klein (2012), investment is not an adequate substitute for the opportunity construct and why opportunity beliefs are needed as a stimulus for entrepreneurial action. Next, I explain 
how judgment remains an effective analytical device even after a theoretical shift from viewing entrepreneurial judgment as a single grand prediction to conceptualizing it as the capacity to form conclusions based on social inferences that are frequently tested and updated as one progresses through the decision making of entrepreneurial action. As a result, entrepreneurial judgment, in a form that is more circumscribed than that typically found in economic theory, is not only consistent with the effectual logic promoted by Sarasvathy and Dew (2013), but also necessary for effectual logic to function. Finally, I consider some implications the proposed understanding of entrepreneurial judgment as empathic accuracy and a sequential decision-making approach to entrepreneurial action could have on future research in entrepreneurship.

\section{Defining judgment}

Before examining any domain-specific nuances of entrepreneurial judgment, I begin with a definition of judgment in its more generic form and review the literature devoted to its study in the hope of identifying lessons that might be successfully transferred to decision making in an entrepreneurial context.

A common understanding of 'judgment' according to The FreeDictionary online is:

- The mental ability to perceive and distinguish relationships; discernment

- The capacity to form an opinion by distinguishing and evaluating

- The capacity to assess situations or circumstances and draw sound conclusions: good sense; sagacity

In other words, judgment is commonly used to refer to an ability to reach a conclusion through careful analysis. Good judgment is reaching a sound conclusion in a manner other than chance.

Researchers in the field of Judgment and Decision Making (JDM) do not deviate much from this common understanding, but they offer greater precision in defining terms. Hastie (2001) notes:

- Judgment refers to the components of the larger decision-making process that are concerned with assessing, estimating, and inferring what events will occur and what the decision maker's evaluative reaction to those outcomes will be.

- The primary standards for the quality of judgment are based on accuracy, the correspondence between judgment and the criterion condition that was the target of the judgment (Hammond, 1996; Hastie and Rasinski, 1987).

In addition, JDM offers a definitional template for a decision (see Figure 1) wherein:

- Decisions are situation-behavior combinations, which can be described in terms of three essential components: alternative actions, consequences, and uncertain events. 
Figure 1. (Colour online) Definitional template for a decision.

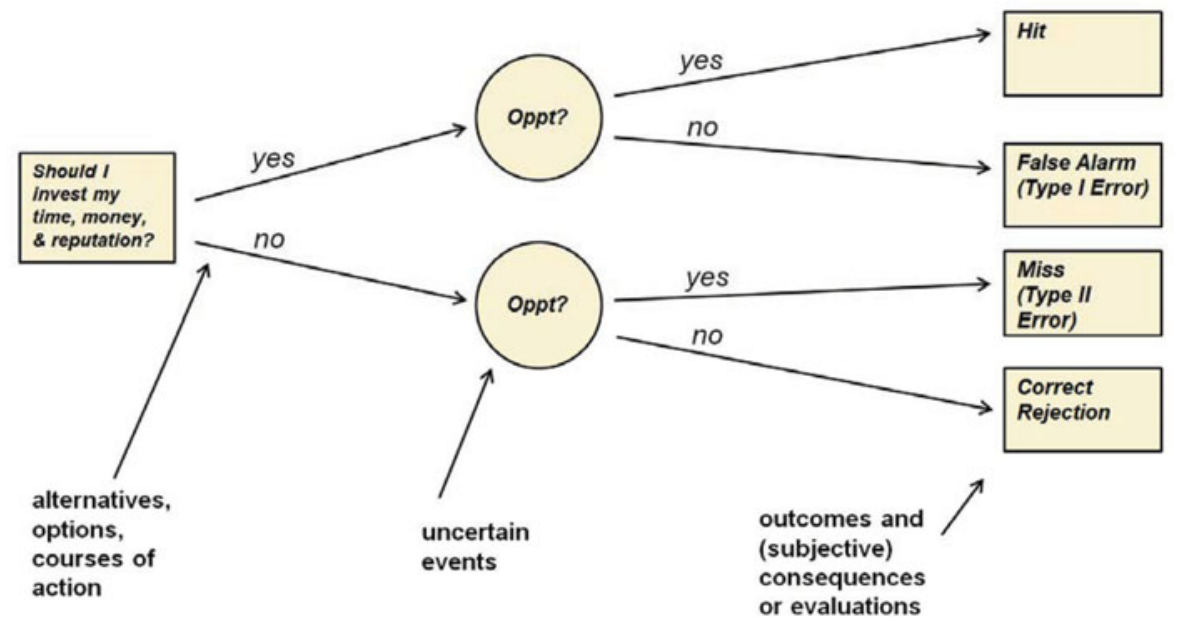

- Outcomes are the publicly describable situations that occur at the end of each path in the decision tree (outcomes may become mere events if the horizon of the tree is extended further into the future). Consequences are the subjective evaluative reactions (measurable on a good-bad, gain-loss scale), associated with each outcome.

- Uncertainty refers to the decision-maker's judgments of the propensity for each of the conditioning events to occur. Uncertainty is described with several, sometimes competing, measures in various decision theories, including probabilities, confidences, and likelihoods. (For prescriptions for precise usage of these terms, see Luce and Raiffa (1957) for an introduction to traditional distinctions.)

- Preferences are behavioral expression of choosing (or intentions to choose) one course of action over others.

- Decision making refers to the entire process of choosing a course of action.

Although JDM is becoming more behavioral, psychological, and descriptive, its boundaries and major theoretical concerns are all related to the historically dominant expected utility family of theories (Hastie, 2001). Central to all these frameworks is a distinction between information regarding what the decision maker wants (often referred to as utilities) versus what she believes is true about the situation (often called expectations) (Hastie, 2001).

There are at least two important limits on the expected utility framework. First, it is incomplete. Hastie (2001: 658) explains:

The framework says nothing about how the decision situation is comprehended or constructed by the decision maker: which courses of action are under consideration in the choice set? In addition, the theory says nothing about the sources of inputs into the decision process: What should the trade-off be 
between adaptive flexibility and the precise estimation of optimal choices by a realistic computational system (the human brain) in a representatively complex, nonstationary environment? Where does information about alternatives, consequences, and events come from in the first place, and how is it used to construct the representation, on which the expected values/expected utilities are computed? Finally, how are personal values, utilities, and satisfactions inferred, predicted, and known?

Second, the framework does not provide a valid description of the details of human decision-making process. Hastie (2001: 658-659) observes:

Today a myriad of qualifications is applied to the basic expected utility model when it is used to describe everyday decision-making behavior. As the saying goes, compared to the assumptions of the rational model, people are boundedly rational and moderately selfish, and they exercise limited self-control. (Joll et al., 1998)

One of Hastie's (2001) 16 problems for the field of JDM is that it would be useful to develop a theory that provides an integrated account of one-shot, well-defined decisions (current theories) and sequences of linked decisions in a dynamic, temporally extended future. He adds:

Most current decision theories are designed to account for the choice of one action at one point in time. The image of decision maker standing at a choice point like a fork in a road and choosing one direction or the other is probably much less appropriate for major everyday decisions than the image of a boat navigating a rough sea with a sequence of many embedded choices and decisions to maintain a meandering course toward the ultimate goal (Hogarth, 1981). This is exactly the image that has dominated analysis in research by psychologist and computer scientists concerned with problem solving and planning: a problem space composed of a series of problem states with connecting paths, with the problem solver navigating from start to goal and relying on evaluation functions for guidance (Newell and Simon, 1972). Each move from one state to the next can be treated as a decision, with the evaluation function serving to define expected utilities for the alternative moves to each available next state. Sometimes choice in the current situation involves a sequence of decisions that are dependent on each other and on changing the future. This issue of projection and, especially, controllability of the anticipation sequence of decision is frequently mentioned in strategic managerial contexts; however, we do not have much factual knowledge about these decisions or a clearly specified theoretical framework to account for empirical findings. (Brehmer, 1996; March and Shapira, 1992; Shapira, 1997)

Hastie's summary of judgment and decision-making research identifies contributions that the field of JDM could make to the study of entrepreneurial judgment and that the study of entrepreneurial judgment could make to JDM. First, the decision template portrayed in Figure 1 offers a framework that can 
bring additional rigor to entrepreneurship research that is interested in examining how individuals decide whether to initiate and/or persist in entrepreneurial action. Second, Hastie's concerns about the completeness and ecological validity of JDM research highlight a need for JDM researchers to study the kinds of environmental conditions under which entrepreneurial judgment is frequently exercised. For example, the decisions of whether to engage or persist in entrepreneurial action regularly involve the type of complex, non-stationary environment that accentuate the difficulty of deciding what the trade-off should be between adaptive flexibility and the precise estimation of optimal choices. Common sayings such as 'the window of opportunity is closing' speak directly to this tension. Finally, Hastie's efforts to encourage JDM researchers to examine sequences of linked decisions in a dynamic, temporally extended future may offer not only a promising path forward for JDM researchers but also a possible resolution to the debate about the role of judgment in entrepreneurial action, which I now turn attention to addressing.

\section{Entrepreneurial action as a process that requires judgment}

Judgment is exercised when making a decision, but there is controversy in entrepreneurship theory about the stimulus of this decision. What are entrepreneurs judging? Is it an opportunity, an opportunity belief, an investment, or something else entirely?

Since 2000, 'opportunity' has been the frontrunner in garnering the attention of entrepreneurship scholars. In their attempt to propose a distinctive domain for entrepreneurship research, Shane and Venkataraman (2000) borrowed significantly from Kirzner's (1997) understanding of the market as a process in which the function of the entrepreneur was the act of opportunity recognition. As a result, scholars began to examine why some individuals, but not others, recognized, evaluated, and exploited entrepreneurial opportunities, which they defined as 'those situations in which new goods, services, raw materials, and organizing methods can be introduced and sold at greater than their costs of production' (Casson, 1982; Eckhardt and Shane, 2003; Shane and Venkataraman, 2000: 220).

McMullen and Shepherd (2006) responded to this emphasis on opportunity recognition by pointing out that individuals can only believe (not know) that they have recognized entrepreneurial opportunities under uncertainty and that subsequent action is therefore required to prove that this belief is justified (see also Gregoire et al., 2010a, 2010b; Shepherd et al., 2007). Consequently, they proposed that entrepreneurial action, as opposed to opportunity recognition, should be the focus of the emerging field because, in order to become an entrepreneur, an individual must form, evaluate, and act on an opportunity belief. Whether this opportunity belief is indeed an entrepreneurial opportunity can only be determined by the realization of profit or loss generated by action. 
This sentiment was echoed by Klein (2008) who argued that actions, not opportunities, should be the unit of analysis in entrepreneurship studies because under uncertainty, 'opportunities' can only be defined ex post (see also Dimov, 2011).

In developing their theory of entrepreneurial action, McMullen and Shepherd (2006) began a discussion about the nature of this stimulus in which they noted that opportunities are treated objectively by Kirzner (1973) and the management literature (e.g., Shane, 2000; Shane and Venkataraman, 2000). Although McMullen explores the subject further in subsequent papers (see Companys and McMullen, 2007; McMullen et al., 2007), Klein (2008) suggests that this misses the point and is later joined by Foss to argue that ' $[t]$ he notion of "opportunity" is metaphorical, not literal, and emphasis on opportunities can be misleading'. They add:

Microeconomic theory, for example, deals with agents' subjective preferences, but preferences are not observed in action, only behavior in markets. Preferences are inferred from choices made, and there is little need to say what preferences 'are', in some deeper, ontological sense. Opportunities, likewise, do not exist, but are inferred (ex post) from market behavior - if action generates net profit, we say that the actor seized an opportunity. (35)

Consequently, Foss and Klein (2012:35) propose that 'opportunities' be replaced with the more parsimonious concept of 'investments' when theorizing about entrepreneurship.

Although I agree with this sentiment - as evidenced by my advocacy for studying entrepreneurial action in lieu of opportunity recognition (McMullen and Shepherd, 2006), it is important to recognize that an investment is an inadequate conceptual substitute for opportunity. Investment is a response, and if judgment is an operant, then one is left with a decision maker without a decision to make because there has been no stimulus identified as responsible for evoking the need for judgment. If the question is 'Should I invest in this?' then 'this' represents some sort of stimulus, whether objective or socially constructed. To address this stimulus problem, McMullen and Shepherd (2006) introduced the idea of opportunity beliefs as an ontologically neutral representation of this stimulus and noted that a more precise conceptualization of the opportunity belief construct as either an exogenous change in environment (e.g., a new technology) or an endogenous change in mind (e.g., expectations) is likely to require the theorist to take a stronger ontological stance about the objectivity versus the subjectivity of these opportunities (Companys and McMullen, 2007) and as a consequence, a more definitive position on the nature of social reality and whether individuals can influence how it unfolds (McMullen et al., 2007). 


\section{Opportunities as situations that enable advancement of goals}

All opportunities are situations, but not all situations are opportunities. Opportunities consist of environmental conditions (situations) that are interpreted as opportunities when those conditions allow advancement of goals. An opportunity is always an opportunity to do something. Whether discovered, created, or imagined, a situation does not represent an opportunity unless that situation enables the advancement of a goal. ${ }^{1}$

An opportunity is a situation that provides the environmental conditions for anyone with the necessary motive and means to convert a goal into behavior (McMullen and Shepherd, 2006). This goal may be specific and well-articulated (Locke and Latham, 1990) or ambiguous and more closely akin to a motive or unarticulated desire (Lewin, 1999; March, 1982), but either way the situation offers a means to advance an end. Similarly, the goal can significantly predate the situation (like in a premeditated murder) or the situation can evoke the manifestation of a motive in the form of a goal a moment before the act (like in the heat of passion) (McMullen and Dimov, 2013), but again both elements situation and goal - are needed for an opportunity to exist.

An opportunity is a situation that is interpreted in a particular way, but this interpretation is determined by the goal pursued, not necessarily the individual who selects that goal. For instance, the creation of teleportation technology would be a situation that could be interpreted as an opportunity for anyone seeking to reduce the time spent either traveling or shipping materials. The motive for selecting the goal of teleportation technology may vary (profit, charity, etc.), the means (technical expertise, financial capital, organizational readiness, strategies, etc.) used to form or pursue the goal may vary, even the goal itself may vary such that the same situation offers different opportunities for advancing different goals (reducing travel time, reducing shipping costs), but the fact remains that if an individual possessed the motive and means needed to form and act on a goal, the situation would offer an opportunity to convert that goal into behavior that would advance goal pursuit, if pursued. Therefore, a new technology, for example, can represent a situation that enables the advancement of a number of goals simultaneously and can therefore constitute a number of objective opportunities simultaneously (McMullen et al., 2007; Shane, 2000, 2011).

Regardless of whether opportunities are conceived of as objective or subjective, they remain interpretations - a categorization of a situation based on whether that situation is instrumental to advancing some goal (Barreto, 2012). In turn, whether these interpretations are considered objective or subjective depends largely on how abstract (versus specific) and widespread (versus idiosyncratic) the goal is through which this situation is being interpreted (McMullen et al.,

1 Conversely, a situation does not represent a threat unless that situation encumbers, obstructs, or prevents the advancement of a goal. 
2007). For instance, the goal of realizing accounting profit is both abstract and widespread, making it less subjective than, say, the goal of profiting by creating the world's largest online book retailer. Accounting profit is abstract in that it is an event outcome that can be achieved by engaging in a seemingly infinite array of behaviors intended to either increase revenues or decrease expenses (Stieber and Primeaux, 1991). It is widespread in that many agents throughout the economy are pursuing the goal. To the extent that a situation allows advancement of this goal, it is an objective opportunity. For example, when Mosaic made the internet user friendly for the first time, a situation objectively existed in which numerous agents seeking profit were able to use the internet as a means to their ends. However, the objectivity of this opportunity was fully dependent on the existence of the goal. Without the goal, there was nothing to make Mosaic salient, to guide attention to it, and to pull this particular data point from the perpetual flux of data that characterizes human existence and agency (Chia, 2000: 517; Emirbayer and Mische, 1998; Weick et al., 2005).

\section{Distinguishing between opportunities to try and opportunities to succeed}

Viewing opportunities as situations that enable advancement of goals establishes the potential for the successful realization of an event outcome (e.g., profit), but it does not establish the existence of a stimulus for entrepreneurial decision making. That is, opportunity according to this understanding remains an outcome or consequence of the action of investing, not a stimulus that requires a decision maker to exercise judgment. If opportunities are only understood to exist upon successful realization of an event outcome, all the events that led to this conclusion become subservient to it, details within a larger story arc. Similar to the way Cliff's Notes summarize a complex novel, such as War and Peace, Figure 1 collapses a sequence of decisions, each consequential in its own right, into a single decision seemingly made at some point of inception when the entrepreneurial journey was conceived. Retrospection begins with success and then extracts salient events that were instrumental to this outcome, but ex ante, the actor and the researcher observing them do not know the outcome and therefore cannot extract these moments (McMullen and Dimov, 2013). One cannot exercise judgment (good or bad) at Time 0 about an event outcome realized at Time 10 when many (most or all) of the environmental conditions that led to the outcome likely did not exist at Time 0 , and possibly did not even exist as of Time 9 for that matter.

For this reason, it is important to make a distinction between opportunities to realize an event outcome (e.g., profit) - i.e., 'an opportunity to succeed' - and opportunities to engage in action - i.e., 'an opportunity to try'. McMullen et al. (2014) illustrate the difference:

A young man may have the goal of asking a young lady out on a date but lack the opportunity until they are both invited to a party. At that party he may meet her 
and even have a conversation but lack the courage to ask. This failure does not negate the existence of the opportunity to complete the goal, despite his failure to seize it. Therefore an opportunity to engage in action can exist regardless of the subsequent success or failure of the action or whether the action takes place at all. Whether the situation is recognized as an opportunity still depends on the decision maker being aware that he is confronting environmental conditions that allow him to convert his goal into action, but action, not some outcome generated by it, is all that is needed to verify the existence of the opportunity.

By contrast an opportunity to realize an event outcome such as meeting one's soul mate is contingent on another's beliefs, preferences, and behavior over time. Accurate social inference in this scenario is necessary in order to realize a successful event outcome. Therefore, the focal agent has no way of knowing whether the situation is an opportunity before action proves it to be so. The focal agent may believe that the situation is an opportunity to realize a successful event outcome and ask the girl out. She may say no, refuting the belief that the situation was an opportunity to realize a successful event outcome. She may say yes, only to say no to a second date or for the young man to realize he was mistaken in his belief such that he chooses not to ask her out for a second date. They may even date for years, marry, and divorce years later. This could refute the belief that this girl is his soul mate. Obviously, an opportunity to realize a successful event outcome represents a much higher bar than an opportunity to engage in action, which it encompasses.

Thus, a distinction needs to be made between opportunities to succeed which can only be determined post hoc and opportunities to try which can be identified ex ante. Opportunities to succeed cannot exist without opportunities to try. An accumulation of responses to 'opportunities to try' eventually result in success or failure. If a successful event outcome is realized, these 'opportunities to try' are then retrospectively interpreted as 'opportunities to succeed'. In essence, 'opportunities to try' are the situations about which entrepreneurial decisions are being made. They represent the opportunity beliefs that comprise the more detailed plot of the overarching story portrayed by Figure 1 and distilled into a Cliff's Notes version of entrepreneurial action.

An opportunity to try is a situation that allows for action, an attempt to advance toward a goal. Not all opportunities to try result in an opportunity to succeed. An opportunity to succeed is a situation that allows for the successful realization of an event outcome. It is an attempt with a specified outcome - profit. For many, with the motive and means needed to engage in goal pursuit, Mosaic made the internet accessible to the masses and therefore represented an opportunity to try, but not necessarily an opportunity to succeed; in other words, it was not a profit opportunity for all who tried. Although the situation represented an opportunity to try that prompted a number of people to form opportunity beliefs, it represented an opportunity to succeed, a profit opportunity, for only a few. Conversely, it may have represented a missed 
opportunity for some of the population who had the goal, but lacked the means (e.g., awareness or access to the situation) or enough motive to form and/or exploit an opportunity belief.

Opportunities to try are all that can be identified under conditions of uncertainty, but that is not to say that opportunities to succeed do not objectively exist. Clearly they do or we would not have advances in science and engineering that lead to growth in knowledge and the Pareto efficient improvements needed for economic growth. However, as McMullen and Shepherd (2006) point out, entrepreneurs simply cannot know this beforehand. They must prove it through action. They can form a belief that the situation will lead them toward their end goal of profit, but this belief typically initiates a journey that transpires over time, is not over in an instant, and it is largely open-ended (McMullen and Dimov, 2013). It is this journey that is too often ignored by economic theory, which often uses entrepreneurship as a mechanism for explaining how a dynamic economy achieved market coordination, development, or growth, after the fact (e.g., Kirzner, 1973; Schumpeter, 1934).

To the extent that there are situations that allow for advancement of goals, independent of whether individual decision makers choose to select those goals, opportunities to try exist objectively and can be identified ex ante. To do so, individuals form opportunity beliefs that they evaluate and exploit. When this exploitation advances the entrepreneur toward some greater end-goal, such as profit, these opportunity beliefs are justified, but opportunity beliefs can lead to losses as well as gains, such that action refutes the claims advanced by these opportunity beliefs. Action provides evidence that supports or refutes the quality of the judgment used to evaluate and act on opportunity beliefs (Shepherd et al., 2012). If the Cliff's notes version of entrepreneurial action is expanded such that time is decompressed to its full text version, we begin to recognize the flaws of economic theories of entrepreneurship. Just as importantly, however, we begin to realize how decision sequencing might offer deeper insight into the content of entrepreneurial judgment, such that it does not have to remain 'an unfathomable mystery of life and mind'.

\section{Is entrepreneurial judgment unnecessary?}

Two primary issues arise from the retrospection of economics' explanatory approach to entrepreneurship theorizing, and despite being on opposite sides of the fence regarding the importance of entrepreneurial judgment, both Sarasvathy and Dew (2013) and Foss and Klein (2012) take issue with Kirzner's (1973) theory of entrepreneurial alertness for promoting these errors. First, by starting with the present and looking backward to the past to explain how today's consequences emerged from yesterday's actions, a universe of counterfactual possibilities are lost that may have been equally feasible or viable at the time of decision, even if they were not as desirable as the revealed preference (McMullen 
and Dimov, 2013). Too often the economy is explained in terms of variance across individuals as they respond to the same opportunity, and the present is viewed as the inevitable consequence of the past such that opportunities to succeed are assumed to have been the product of some entrepreneurial capacity for foresight that some possessed and others lacked. This view treats entrepreneurs as investors who have no control over outcomes but instead merely seek to pick winners from losers. Consequently, it neglects the importance of agency in entrepreneurship and eliminates the potential for course corrections based on feedback from the environment. As a result, opportunity becomes a deterministic and overly structural concept.

For example, some scholars (e.g., Kirzner, 1973) begin with the socioeconomic order they observe around them and then seek to trace its source back in time. The result tends to be a somewhat deterministic understanding of the social world in which the emergence of particular technologies, political upheavals, or social movements is depicted as inevitable (Dimov, 2011). This view offers an elegant portrait of socio-economic order, focusing on the fully blossomed opportunity and then explaining it in terms of the seed of an entrepreneurial idea. An entrepreneur leads the change effort, introducing the new idea that will ultimately shape social reality, but the particular individual assuming this agency is considered inconsequential (McMullen and Shepherd, 2006). Focus is entirely on what an entrepreneur does, not on who does it. Indeed, the guiding mantra of this approach appears to be captured best by Victor Hugo: 'Nothing is more powerful than an idea whose time has come'. The idea, not its originator, is considered the impetus of systemic change, and this idea is largely a function of the structural changes occurring within society. Johnson (2010), for example, points out that many people coincidentally come up with a profoundly new idea at the same time despite no connections to each other.

Because structural change is occurring as the consequence of action (Holcombe, 2003b), it is considered responsible for both the idea and the conditions needed to enact it. As a result, Kirzner (1973) places emphasis on the entrepreneurial alertness in which new information about environmental conditions evokes a realization that previous valuations of various means-ends frameworks are now erroneous and in need of correction. ${ }^{2}$ According to this structural approach, it was structural change that inspired both a widespread dream of equality and the conditions to fulfill it that led to the civil rights movement; Martin Luther King, Jr. gave the dream a voice and Rosa Parks triggered the movement, but had they not filled the role of change agent provided by the trends of the day, someone or something else would have.

2 Kirzner (1982) later seeks to extend this view to decisions under uncertainty, but as High (1982) points out, the theory is best circumscribed to conditions of ignorance. 
The 'entrepreneur', conceived as an agent of intentional change, merely had to realize potential that existed, where it did not exist before.

I suggest that this deterministic conception of opportunity is flawed. Opportunity is not an oak tree born of an acorn of an idea. It is more like a stem cell that can grow into a host of body parts given the necessary environmental conditions. Using the stem cell analogy, it is much more difficult to look at the body part and determine the nature of its originating cell. If opportunities were like an acorn, then the question would merely be: which environmental conditions encourage or discourage the seed from fully developing? The entrepreneurial vitality of an economy would then rest primarily in individuals' willingness to assume the role of the entrepreneur and the only true judgment being exercised would be about whether the individual has the means and motive to recognize and exploit the opportunity, but whether exploitation of the situation resulted in a profit opportunity would not depend on the agency of any particular actor.

Foss and Klein (2012: 35) correctly note 'the worst that can happen to an entrepreneur' according to Kirzner's formulation is 'the failure to discover an existing profit opportunity. Entrepreneurs either earn profits or break even, but it is unclear how they suffer losses'. This lack of potential for loss troubles Foss and Klein (2012) who use the uncertainty construct to reconcile the theory of the entrepreneur with the theory of the firm, noting that 'Because they own no assets, [Kirzner's entrepreneurs] bear no uncertainty' (34). If the entrepreneurial function is defined as opportunity recognition, and an opportunity is guaranteed to succeed, then resources mobilized to exploit it cannot be at risk, and no uncertainty must be borne to engage in entrepreneurial action. Though I agree with this logic, I do not believe the resources at risk must be material for the entrepreneur to bear uncertainty.

Entrepreneurial action is a response to judgment exercised under uncertainty about whether investing one's time, talent, and or treasure in pursuit of a new course of action will provide a utility improvement over the status quo (Shepherd et al., 2007). Moreover, because this is 'entrepreneurial' action (as opposed to human action), this utility improvement is contingent on providing an improvement in utility for other stakeholders as well (McMullen, 2010, 2011). ${ }^{3}$ This suggests that the judgment exercised in entrepreneurial opportunity evaluation is about a new transaction whose viability is contingent on all stakeholders realizing utility if not profit. Expected returns and their perceived attractiveness are likely to be influenced by the alternative opportunities for action that are imagined to be and actually are available to customers, the entrepreneur, and other stakeholders, these alternative opportunities for action

3 I am merely referring to Pareto efficiency, not Pareto optimality (see Holcombe, 2003a for an explanation of the difference). 
are provided by the socio-economic conditions in which these various agents are structurally embedded (Granovetter, 1985).

The second problem with the explanatory approach is that looking backward glosses over the many decisions that culminate in the realization of profit. This makes it look as though the entrepreneur made a single decision of whether to engage in entrepreneurial action and that good judgment in exercising that decision was solely responsible for the profit later realized. Sarasvathy and Dew (2013: 292) argue, 'Entrepreneurial judgment, in its conventional form, is in fact neither necessary nor sufficient for entrepreneurship'. They seek to replace it with an effectual logic in which judgment is not conceptualized as a 'thing, not an attribute of individuals, but the cumulative residual of a dynamic and interactive process the activation and fostering of which in itself can be precisely and simply specified' (Sarasvathy and Dew, 2013: 291). That is, they offer a conceptualization of entrepreneurial judgment that is essentially procedural in the form of an effectual logic. Sarasvathy and Dew (2013: 291-292) expound:

Effectual stakeholders are less likely to play a game of follow-the-vision (Witt, 1998a, 1998b) or plan (Sautet, 2000) of the charismatic entrepreneurial leader and more prone to negotiate a variety of concrete stakes in shaping vision and venture. In any case they self-select into the process and pay a price (in the form of a pre-commitment) to self-select. In this sense, every effectual transaction is a market transaction. Whether it is a straight transaction where the stakeholder is buying the 'vision' that the entrepreneur is selling and seeking only to influence its execution, or whether it is a completely counterfactual transaction where the stakeholder is buying an option to shape that vision itself, the heart of the effectual process is a negotiated market transaction. No coercion, no fiat and - in the most effectual cases - not even a hard sell. Effectuation leverages individual imagination, but leaves room for and in certain cases highlights the importance of cooperative action in the creation of enduring firms and hierarchical coordination in keeping them going. But the way forward with effectual cooperation and coordination is mostly the way of Amartya Sen's solution to the social choice problem - i.e., a leveraging of individual freedoms and capabilities to choose ends as well as means and the voluntarily and strenuously take 'other minds' into account in making those choices. (Sen, 1999)

Sarasvathy and Dew (2013) equate entrepreneurial judgment to a process of negotiated co-creation. The purpose of effectuation may not be to achieve a goal, but that does not mean that entrepreneurial action is random. People have reasons for actions - reasons that consist of beliefs and desires. Even in effectuation, an entrepreneur will not initiate a novel transaction unless he believes the other party is likely to have some stake in the outcome of the proposed endeavor. Thus, before approaching potential customers or investors, entrepreneurs must choose one target over another based on their own belief that the target will agree that the new value proposition has some impact on his or her 
desires. This requires the entrepreneur to imagine who might be impacted in the future by the new customer value proposition and how they might be impacted were the proposition to be introduced successfully to the market (McMullen, 2010).

Although they claim that entrepreneurial judgment is not an ability, Sarasvathy and Dew (2013: 292) clearly emphasize the need to 'voluntarily and strenuously take "other minds" into account' when making choices, which is greatly facilitated by an ability known as empathizing. The social competency of empathy facilitates the predictive process of stakeholder selection, whereas accuracy in this empathic effort is likely to encourage the complicit behavior of stakeholders once selected (McMullen, 2010). Thus, few if any agents are likely to develop new products for new markets without some reason for suspecting that customers will buy them. Moreover, many if not all of these agents must communicate their reasons to investors or distributors before expending the resources needed to test their new product in the marketplace (Anderson et al., 2006). Thus, it seems unlikely that the variation represented by the introduction of a new product is random, haphazard, or blind and more likely that it is speculative in nature and informed to a greater or lesser extent by the entrepreneur's ability to take the perspective of various stakeholders.

Therefore, it seems that Sarasvathy and Dew (2013) did not exorcise entrepreneurial judgment as they imply; instead, they merely encouraged a greater precision in its meaning where scholars have not always been clear about what was being judged. In the case of effectual logic and the opportunity beliefs that serve as the stimuli of the decisions to initiate and persist in entrepreneurial action, it would appear that what is being judged are others' preferences.

\section{Social inference and the shift from predictive to empathic accuracy}

Much of our theoretical understanding of the entrepreneurial function is grounded in a deterministic understanding of socio-economic order in which entrepreneurial action is collapsed into a single moment of decision like that pictured in Figure 1, often described by Kirzner (1973) when discussing entrepreneurial alertness, and criticized above by Hastie (2001) for being unrealistic. Behavioral examination of entrepreneurial action, however, reveals a process that is directed by the desire to achieve a particular goal or effect and sustained over time despite anticipated and unforeseen challenges and obstacles presented by the environment. As such, it is far more reminiscent of Hogarth's (1981) analogy of a boat navigating a rough sea and likely to resemble Newell and Simon's (1972) depiction of decision making as a problem space composed of a series of problem states with connecting paths, with the problem solver navigating from start to goal and relying on evaluation functions for guidance.

As a result, there is a need to replace or reconcile the image in Figure 1, which is often used in economic theories of the entrepreneur, with the framework pictured 
Figure 2. (Colour online) Entrepreneurial action as effectuation.

\section{EFFECTUATION IN ACTION}

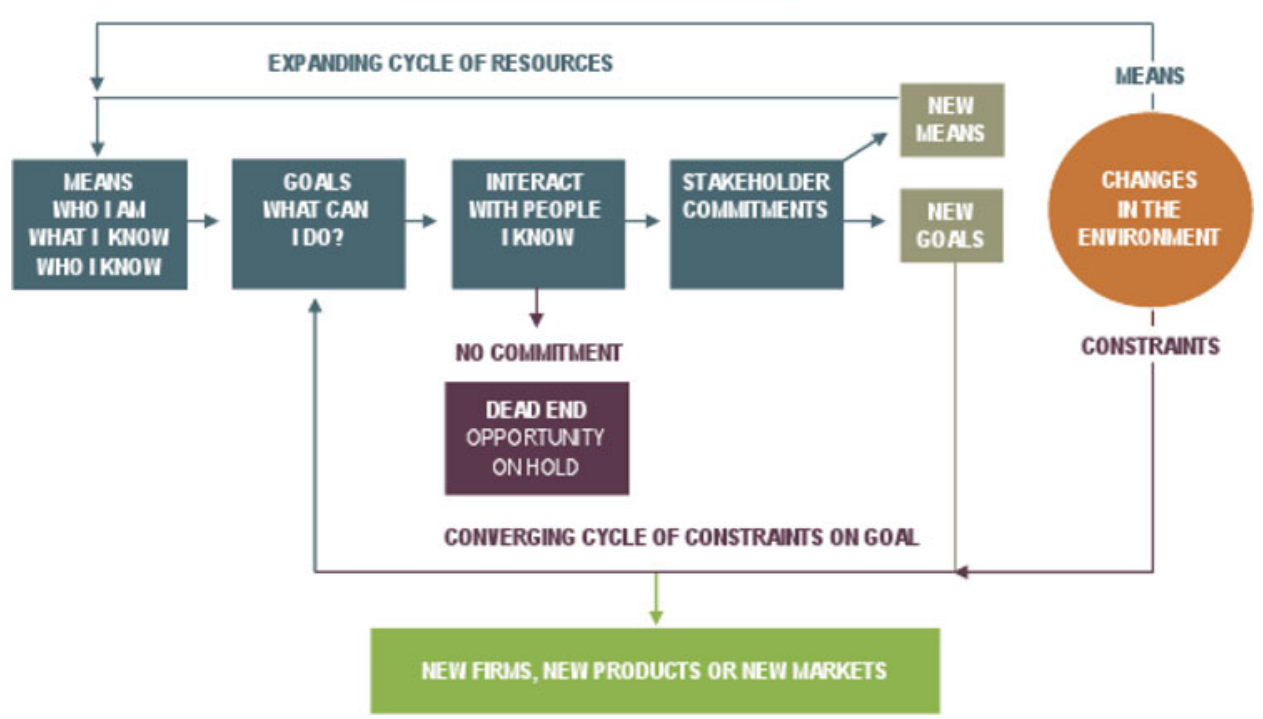

in Figure 2, which offers a behavioral understanding of entrepreneurial action witnessed in the field. Figure 2 is a graphical depiction of the effectual framework advocated by Sarasvathy and Dew (2013) but first introduced in Sarasvathy and Dew (2005). For effectuation, entrepreneurial judgment is, in effect, a process of negotiation, but this behavioral understanding cannot fully replace cognitive underpinnings that enable it. Regardless of whether one adopts an effectual framework or employs a highly teleological approach to entrepreneurial action, there are facts about entrepreneurial action that suggest that social judgment and thus empathic accuracy are essential not just for realization of an entrepreneurial opportunity but for the inspiration, ideation, and implementation necessary for the process to begin and endure. For example, zealous advocates of effectuation often argue that it is non-teleological (Sarasvathy, 2001), but the entrepreneur must still choose to approach one person over another when seeking investors, customers, suppliers, distributors, etc. in order for the desired effect to have any hope of being satisfied regardless of the goal used to achieve this satiation (McMullen, 2010). Such progress is contingent on social judgment, which is facilitated by empathic accuracy (Chiles et al., 2010; McMullen, 2010). Thus, the social nature of entrepreneurial action implies that entrepreneurial judgment may differ somewhat from a more generic form of judgment. For example:

- Entrepreneurial judgment implies a transaction which in turn requires an interaction between two different decision makers.

- This interaction necessitates some degree of communication between parties which in turn implies some level of understanding of another's viewpoint and interests. 
- Understanding necessitates some degree of cognitive or affective empathy which in turn implies enough imagination to take another's perspective.

- Finally, this empathic imagination is likely to depend partly on current perceptions and memories of experiences with the focal other and/or non-focal others.

In addition, empathic imagination is likely to be extended not just to people but to events. For example, the entrepreneur does not always have the privilege of negotiating through personal interaction. Sometimes he or she must make decisions based on inferences of what others will do without being able to lock them up in pre-commitment. Consider, for example, the problem of scale. Ultimately, scale of a product or service requires that the entrepreneur's innovation must, at some point, transition from a personal exchange to an arm's length transaction. Because empathic imagination is not limited to specific targets, but instead can be extended to strangers, figments of the imagination, animals, or even objects (through, for example, anthropomorphizing) it can enable transcendence of specific concrete targets to vaguely defined abstract demographic or psychographic targets, such as 'they' or 'the market'.

\section{Entrepreneurial judgment as empathic accuracy}

Empathic accuracy is 'the ability to accurately infer the specific content of other people's thoughts and feelings' (Ickes, 1993; Ickes et al., 1990). As a form of complex psychological inference in which observation, memory, knowledge, and reasoning are combined to yield insights in the thoughts and feelings of others, empathic accuracy is a fundamental dimension on which ones' social intelligence can be assessed as can the measure of one's skill in empathetic inference (Cantor and Kihlstrom, 1987; Goleman, 1995; Goody, 1995). Empathic inference, in turn, is 'everyday mind reading' (Ickes, 1997: 2), such that empathically accurate perceivers are those who are consistently good at 'reading' other people's thoughts and feelings.

Empathy can manifest as either an emotional reaction to or a cognitive understanding of other people's experiences (Duan and Hill, 1996). This 'emotional empathy' is comprised of empathic concern and emotional contagion. It refers to 'an others-focused emotional response that allows one person to affectively connect with another' (Galinsky et al., 2008: 378; Ickes, 1997: 164). Referred to as sympathy or compassion on occasion, this form of empathy is often considered to be an emotion of concern experienced when witnessing another person's suffering (Batson et al., 1987). This other-orientation enhances the awareness of others' vulnerable circumstances and a deeper appreciation of context (Dutton et al., 2006; Frost et al., 2000; Lilius et al., 2008). As evidence of valuing the outcomes of others, the other-oriented nature of emotional empathy encourages helping behavior (e.g., Coke et al., 1978; McBane, 1995) even at the expense of one's own self-interest (Batson and Shaw, 1991; Epley et al., 2006). 
The essence of 'emotional empathy' or 'affective empathy' can thus be expressed as 'I feel your pain'.

Cognitive empathy, by contrast, refers to the ability to understand another person's thoughts and feelings (e.g., Barrett-Lennard, 1981; Duan and Hill, 1996; Dymond, 1949; McBane, 1995). It is often referred to as perspective taking, which is a 'cognitive or intellectual process' that often but not always results in the affective response of empathy (Parker and Axtell, 2001: 1087). Ickes (1997: 163 ) refers to it as 'the tendency to entertain the psychological point of view of other people'. By enabling people to consider the world from other viewpoints, perspective taking 'allows an individual to anticipate the behavior and reaction of others' (Davis, 1983: 115). Thus, perspective taking is a cognitive process in which individuals adopt others' viewpoints in an attempt to understand their preferences, values, and needs (Grant and Berry, 2011: 79). The essence of 'cognitive empathy' or 'perspective taking' can therefore be expressed as 'I see your point'.

Empathic accuracy is comprised of four constituents: purpose, sources of information used, processes employed, and outcome (Davis, 2005). Understanding or anticipating another's actions often requires an observer to discern a subject's purpose, which in turn requires an observer to achieve some understanding of a target's point of view. Empathy facilitates this process by allowing observers to infer targets' thoughts, intentions, or goals from information about the target, the environment, or themselves. The target's facial expressions, posture, voice, statements, and actions provide the richest sources of information used in social inference. These are complemented by information about the target's physical and social environment. Finally, observers may draw from knowledge about the social categories to which the target belongs or from similar situations, cognitive and emotional states shared with the target, or prior experiences with the target.

Empathic attempts may employ processes that range in consciousness from unconscious through automatic to deliberate. For example, involuntary practices involve physically mimicking others' facial expressions, whereas automatic processes may include projecting one's own states or traits onto others. Of the three processes, however, controlled processes, such as logical inference, simulation, and imaginative processes in which observers 'deliberatively attempt to construct in their own minds what the experience of the other is like' (Davis, 2005: 47), are likely to be most relevant to the entrepreneurial process (McMullen, 2010).

The final constituent of empathic accuracy is outcome. It can manifest cognitively by producing greater accuracy in judging the target (e.g., Bernstein and Davis, 1982), motivationally by valuing the target's welfare more (Batson et al., 1995), or behaviorally by anticipating others' reactions successfully to improve social effectiveness (e.g., Davis and Kraus, 1991). Given that all three of these outcomes are likely to facilitate the entrepreneur's ability to anticipate 
others' preferences, it would seem that empathic accuracy would facilitate progress through the early phases of the entrepreneurial action process in which the entrepreneur generates an idea and must decide whether to invest additional resources into its development (Koen et al., 2001; Smith and Reinertsen, 1997). As Everett Rogers (1995) points out, 'If the adopter of an innovation is faced with a high degree of uncertainty, the inventor-developer of a new idea must understand not just his or her own problems but also anticipate the problems of various other individuals and organizations who will be the ultimate adopters of the innovation' (137-138). Because thinking of a problem from another's perspective activates different regions of the brain than thinking about that same problem from one's own perspective (Ruby and Decety, 2001, 2003), entrepreneurs are likely to allocate attention differently when imagining how consumers or stakeholders will evaluate a product idea (Piaget and Inhelder, 1956; Ruby and Decety, 2004). By considering different constraints, entrepreneurs experience a more comprehensive examination of the problem as well as enhanced creative potential as a result of additional informational inputs (Smith and DiGregorio, 2002; Veryzer, 2003). This potential, however, does not necessarily lead to unfocused fancy because empathy can also manifest as a 'voice of judgment' within internal dialogue that serves to test solutions against the backdrop of stakeholder acceptance (Chiles et al., 2010; Seely Brown and Duguid, 1992). This presents a tension in which too little judgment can yield too little discipline, while too much can stifle the creative process (Ray, 2004).

As an entrepreneur articulates a new product idea, definition of the target market emerges (Cooper, 2001). To infer what product features will resonate with members of a particular group entrepreneurs must simulate (deliberately or automatically) others' decision making by imagining what that target believes and desires (Webb, 1996). A range of stakeholders must accept an innovation if it is to spread (Oudshoorn et al., 2004: 31). By anticipating stakeholders' interests, entrepreneurs can use empathy to help tailor the design of their new product and to employ rhetoric that helps explain it in ways that reduce resistance among various individuals and constituencies (Rogers, 1995; Seely Brown and Duguid, 1992). As a result, empathy transcends salesmanship to shape the idea itself so that it is more appealing to potential partners and customers and less threatening to potential competitors (Thomke and Fujimoto, 2000).

Thus, empathic accuracy is useful in both the feedforward and the feedback processes of entrepreneurial action. In the feedforward phase it helps entrepreneurs to understand the wants and needs of others, as well as the problems and constraints that are currently preventing those wants and needs from being better fulfilled. To the extent that an entrepreneur can generate solutions for overcoming these problems and constraints to offer superior product solutions, empathy, especially in the form of perspective taking, is likely to facilitate idea generation and the setting of goal intentions that are superior to the status quo. Within the context of entrepreneurial action, these goals 
have been conceptualized as opportunity beliefs (Gregoire et al., 2010a, 2010b; McMullen and Shepherd, 2006). Just as an opportunity belief is not necessarily an opportunity, a goal intention is not equivalent to successful goal completion. Upon setting a goal intention, the entrepreneur must engage in the feedback process in which he or she navigates uncertain environmental conditions in the effort to justify an opportunity belief through action. Empathic accuracy is essential in this feedback process. A customer value proposition has to be compelling enough to investors or donors for them to fund the venture. Likewise, it has to be compelling enough to employees for them to join the venture, and for suppliers and distributors to source its inputs or deliver its outputs. Each of these encounters is likely to involve communication, cooperation, negotiation, and even persuasion, and each of these skills is facilitated by empathy, such that empathic accuracy could be expected to facilitate implementation of an idea once generated and diffusion of an innovation once introduced.

\section{Limitations of empathic accuracy}

Empathic accuracy may prevent as well as facilitate entrepreneurial action. If entrepreneurial action is always a break with the status quo, then it is likely to involve some degree of innovation for the individuals involved, even if it is well-trodden ground for society as a whole. To seize an opportunity is to reject the status quo in favor of the novel. Therefore, institutionally speaking, innovation is socially deviant behavior at the individual level, if not at higher levels of socio-economic order.

Because empathy makes individuals highly sensitive to what others think and feel (Davis, 1983), and because uncertainty prevents the masses from perceiving that a situation represents an opportunity worthy of investment of their time, talent, or treasure (McMullen et al., 2007), it is possible that empathy may actually prevent individuals from attempting entrepreneurial action, for fear of what others would think if the entrepreneur failed. It would seem logical to expect individuals high in empathic imagination to also be highly sensitive to social embarrassment. As a result, they may be more susceptible to fear of failure, thereby preventing them from initiating entrepreneurial action despite their ability to generate and implement ideas for new products. Researchers may want to examine this possibility in the future and determine whether individual differences in confidence, self-efficacy, or egotism serve to moderate the effect that empathic imagination has on the decision to either initiate or persist in entrepreneurial action. It is possible that empathic accuracy facilitated by empathic imagination may be relegated to a facilitative role in which the motivator of action is passion (Cardon et al., 2009), compassion (Miller et al., 2012), or other non-hedonic sources (e.g., Schumpeter, 1934: 91-94), and empathic imagination or the other possible predictors of empathic accuracy would then serve as levies that would channel this motivational current 
toward successfully meeting stakeholders' interests, consequently contributing to the potential advancement of the entrepreneur's interests. Therefore, greater accuracy of others' preferences is likely to facilitate success in entrepreneurial action once initiated, but it will not necessarily encourage the initiation of entrepreneurial action. Moreover, because stakeholders may not realize their preference for a novel action until they confront and make a choice to try the new product offering, it is possible that greater accuracy regarding others' preferences could actually inhibit or suppress the entrepreneur's willingness to try entrepreneurial action that would have succeeded had it been pursued.

I do not offer empathic accuracy as a 'silver bullet' solution to the problem of identifying who will and who will not succeed in entrepreneurship. If the product idea that the entrepreneur is developing is simply inferior to the status quo, then it may not matter how good that entrepreneur is at taking another's perspective. There may be no good way to frame the choice for the customer such that the entrepreneur's product is preferable to the status quo. Empathic accuracy can help influence the design of a product so that the product features that offer a distinctive benefit are accentuated (Anderson et al., 2006), but there still have to be some distinctive benefits if the product offering is going to usurp the status quo. Empathic accuracy helps to communicate these distinctive benefits, but they are often (not always) achieved through some sort of objective improvement, such as the use of superior raw materials (e.g., higher quality ingredients), inputs (e.g., technological improvements), or aesthetic experience (e.g., improved design). Thus, empathic accuracy appears to be helpful in assuaging demand uncertainty (McMullen, 2010), but because entrepreneurial action also poses substantial supply uncertainty (Sarasvathy et al., 2003), especially in arenas such as technology entrepreneurship (Autio et al., 2013), I am not proposing that it answers the question of who will become an entrepreneur or succeed at entrepreneurship. Indeed, it is important that we avoid the error too often made by economic theorists of entrepreneurship wherein variance in entrepreneurial activity gets relegated to a single quality or ability; in this case, empathic accuracy. Empathic accuracy is not sufficient, and it is not necessary to succeed, but it would logically seem to increase the odds. Stacking the odds in favor of success is arguably one of the reasons for entrepreneurship research and becomes increasingly important for entrepreneurs who wish to offer a second successful product or to start more than one firm.

\section{Implications for future research}

Despite these limitations, which are as much of an indictment of (1) the perceived benefits of accuracy under environmental uncertainty (cf. Weick, 1995: 54-56) or (2) a variance-based approach to studying entrepreneurship (cf. McMullen and Dimov, 2013) as they are an indictment of empathic accuracy, it is clear that empathy, especially when informed by empathic imagination, has a role to 
play in entrepreneurial judgment and entrepreneurial action under uncertainty. Four questions come to mind that empathic accuracy and the distinction between micro- and macro-decisions speak to.

First, does empathic accuracy influence undue persistence, such as escalation of commitment? Creation of a new venture often begins with the idea for a new customer value proposition. Research has shown that attention to others' needs is an antecedent of new product ideas (Grant and Berry, 2011). In selling the proposition to investors, entrepreneurs invest considerable energy into empathizing with customers. This empathy can be affective or cognitive. If affective, entrepreneurs run the risk of losing the distinction between their own interests and those of the customer as they identify with the customers to the point that they may sacrifice their own interests to meet those of the target. This could encourage a weakened bargaining position in negotiation with investors and lead the entrepreneur to have to achieve higher financial returns in order to achieve some personally desired threshold of success. Higher target thresholds have been associated with risk seeking. Higher expenses from, say, debt financing would contribute to higher losses if the venture was abandoned, and loss aversion has been shown to be a primary determinant of escalation of commitment. Through this loose chain of events, affective empathy could contribute to a series of micro-decisions that could encourage the macro-decision to engage in undue persistence.

Compared to affective empathy, cognitive empathy (perspective taking) would put the entrepreneur in a better bargaining position. Under the influence of cognitive empathy, entrepreneurs are likely to remain detached and capable of discerning their own interests from those of customers. This should prevent the entrepreneur from being overly eager in negotiations with investors, thereby facilitating agreement at a lower cost to the venture. Consequently, expenses from debt financing would be lower as would the threshold needed to meet the returns that are personally desired. As a result, both risk seeking and loss aversion experienced under cognitive empathy would be less salient than they are under affective empathy. If empathy influences negotiations with numerous stakeholders over the entire process of implementation, as I have suggested it does, then entrepreneurs who rely heavily on cognitive empathy could be significantly less exposed to risk and therefore escalation of commitment than entrepreneurs who rely heavily on affective empathy during bargaining.

Second, does entrepreneurial accuracy influence mission drift? I suggested that empathic accuracy could make individuals highly sensitive to others' evaluations such that they experience a strong fear of failure and social embarrassment. This would suggest that empathic accuracy appears to contribute to the ability but not necessarily the willingness to act entrepreneurially. Others, however, have suggested that empathy in the form of compassion motivates as well as enables, thereby encouraging social entrepreneurial action (Miller et al., 2012). Hybrid organizations such as those that seek to create social value using economic means 
often seek to create both social value and economic value concurrently. Donors contribute resources to advance the venture's social cause, whereas customers tend to provide the venture resources in response to the economic value the venture provides them. Serving customers can lead to self-sufficiency such that the venture achieves viability and operational, if not financial, sustainability. Doing so, however, can allocate limited resources, activities, and attention away from the needs of beneficiaries to the desires of customers, leading to mission drift. Though I explained how empathic accuracy could facilitate the success of entrepreneurial action by sharpening the entrepreneur's social inferences, this said nothing of whose preferences the entrepreneur should be attending to. Is mission drift in hybrid organizations predicated on a shift in empathic imagination from target beneficiaries to target customers? Does something similar happen when a firm goes public such that empathic imagination gets diverted from inferring customer needs to inferring the quarterly earnings expectations of financial analysts? Thus, future researchers may want to examine mission drift based on how limited entrepreneurial attention is allocated when making social inferences about various stakeholder groups.

Third, is empathic imagination the source of the informal institutions believed to encourage socio-economic coordination in a world of individuals who rely on subjective or inter-subjective mental models when choosing to act? The assumption that reality is subjectively experienced does not necessarily require that theorists conceive of opportunities deterministically nor does it necessarily require that formal institutions exist to enable coordination among the plans arising from subjective realities. Instead, I propose that it is because entrepreneurship, by definition, involves a transaction that theorists can allow for demand uncertainty and, yet, still have some semblance of socio-economic coordination. Therefore, judgment as understood through the lens of empathic accuracy fueled by empathic imagination clearly has a role to play in the development of opportunities. Not only does it complement effectual logic, but it enables effectuation to transcend personal exchanges and explain how entrepreneurs initiate the arm's length transactions needed for products to scale into widely diffused innovations. In doing so, empathic imagination may offer a mechanism capable of reconciling 'active minds' with the socio-economic order we witness around us every day (Lachmann, 1971, 1976). Consequently, it may shed light on the 'Lachmann problem' (Koppl, 1998), which asks how socioeconomic coordination is possible given the assumptions that value (Menger, 1950), preferences (Mises, 1949), data (Hayek, 1937), expectations (Shackle, 1979), and interpretations (Lachmann, 1976, 1977) are not only subjective but subject to change over time as result of growth in knowledge. Solutions to the Lachmann problem have emphasized institutions, and have evolved from formal institutions (e.g., laws, contracts) to informal institutions (e.g., norms, share beliefs) (Foss and Garzarelli, 2007; Lewis and Runde, 2007). Empathic imagination appears to offer an explanation for the formation of shared beliefs 
and a mechanism for how they shape thought, behavior, and eventually socioeconomic structures (McMullen, 2010).

Fourth and final, if entrepreneurial judgment is scarce but important to economic performance because it facilitates good investment decisions and an efficient allocation of scarce resources, and if this judgment is simply a matter of cognitive processes, then cannot judgment be equated to human capital such that economic policy makers in government could promote entrepreneurship by investing public funds in education? Instead of conceiving of empathic accuracy as some generic form of human capital that can be enhanced through education, policy makers who wish to generate a high growth economy through empathic accuracy may be better advised to view the idiosyncrasies of structural embeddedness as valuable inputs for judgment and good investment decisions. Like many situations in which information is widely disbursed, a decentralized approach to decision making, such as markets, may be better equipped not only to leverage the idiosyncratic life experiences that enable empathic accuracy but also to realize more efficient allocation of resources as a result of the improved investment decisions facilitated by this empathic accuracy.

\section{Conclusion}

By examining Sarasvathy and Dew's (2013) criticism of Austrian economics' notion of entrepreneurial judgment, this article redefined the judgment dilemma as one of scope rather than existence. Empathic accuracy, enabled by empathic imagination, offers a means of addressing critics without having to deny the existence of such a well-documented phenomenon. As an operant, empathic accuracy yields investment as a response, but this investment is ongoing and not a one-time occurrence. Consequently, the entrepreneur makes numerous judgments about opportunity beliefs that eventually culminate in a new product offered by a new venture. What do customers want and how might they provide a desirable solution? What do stakeholders want and how might they be convinced to seek those desires by cooperating with the entrepreneur? These questions require empathy as entrepreneurs take the perspective of their customers and stakeholders. Empathic accuracy facilitates advancement as entrepreneurs leave the shore of opportunity belief and tack like sailors across a sea of uncertainty to arrive at a post hoc destination deemed profit or loss. Although this journey could be described exclusively in terms of its points of departure and arrival as is often the case in economic theories of entrepreneurship, doing so would misinterpret the destination as pre-ordained, undervalue the skill used to navigate stormy seas, and fail to recognize the contingencies encountered along the way that led to say, the West Indies rather than the East Indies. Given that entrepreneurial action is a complex event involving a new transaction that is likely to involve multiple parties in both production and consumption, it would seem that empathic 
accuracy is an essential skill (if not the essential skill) that makes successful navigation through uncertainty possible.

\section{References}

Anderson, J. C., J. A. Narus, and W. Van Rossum (2006), 'Customer Value Propositions in Business Markets', Harvard Business Review, 84(3): 90-98.

Autio, E., L. Dahlander, and L. Frederiksen (2013), 'Information Exposure, Opportunity Evaluation and Entrepreneurial Action: An Investigation of an Online User Community', Academy of Management Journal, 56(5): 1348-1371.

Barreto, I. (2012), 'Solving the Entrepreneurial Puzzle: The Role of Entrepreneurial Interpretation in Opportunity Formation and Related Processes', Journal of Management Studies, 49(2): 356-380.

Barrett-Lennard, G. T. (1981), 'The Empathy Cycle: Refinement of a Nuclear Concept', Journal of Counseling Psychology, 28(2): 91-100.

Batson, C. D., J. Fultz, and P. A. Schoenrade (1987), 'Distress and Empathy: Two Qualitatively Distinct Vicarious Emotions with Different Motivational Consequences', Journal of Personality, 55(1): 19-39.

Batson, C. D. and L. L. Shaw (1991), 'Evidence for Altruism: Toward a Pluralism of Prosocial Motives', Psychological Inquiry, 2(2): 107-122.

Batson, C. D., C. L. Turk, L. L. Shaw, and T. R. Klein (1995), 'Information Function of Empathic Emotion: Learning that We Value the Other's Welfare', Journal of Personality \& Social Psychology, 68(2): 300-313.

Bernstein, W. M. and M. H. Davis (1982), 'Perspective-taking, Self-consciousness, and Accuracy in Person Perception', Basic and Applied Social Psychology, 3(1): 1-19.

Brehmer, B. (1996), 'Man as a Stabilizer of Systems: From Static Snapshots of Judgment Processes to Dynamic Decision Making', Thinking \& Reasoning, 2(2-3): 225-238.

Cantor, N. and J. F. Kihlstrom (1987), Personality and Social Intelligence, Englewood Cliffs, NJ: Prentice-Hall.

Cardon, M. S., J. Wincent, J. Singh, and M. Drnovsek (2009), 'The Nature and Experience of Entrepreneurial Passion', Academy of Management Review, 34(3): 511-532.

Casson, M. (1982), The Entrepreneur: An Economic Theory, Totowa, NJ: Barnes \& Noble Books.

Casson, M. C. and N. Wadeson (2007), 'The Discovery of Opportunities: Extending the Economic Theory of the Entrepreneur', Small Business Economics, 28(4): 285-300.

Chia, R. (2000), 'Discourse Analysis as Organizational Analysis', Organization, 7(3): 513518.

Chiles, T. H., C. S. Tuggle, J. S. McMullen, D. W. Greening, and L. Bierman (2010), 'Dynamic Creation: Elaborating a Radical Austrian Approach to Entrepreneurship', Organization Studies, 31(1): 7-46.

Coke, J. S., C. D. Batson, and K. McDavis (1978), 'Empathic Mediation of Helping: A TwoStage Model', Journal of Personality \& Social Psychology, 36(7): 752-766.

Companys, Y. E. and J. S. McMullen (2007), 'Strategic Entrepreneurs at Work: The Nature, Discovery, and Exploitation of Entrepreneurial Opportunities', Small Business Economics, 28(4): 301-322.

Cooper, R. G. (2001), Winning at New Products: Accelerating the Process from Idea to Launch (3rd Ed.), New York: Perseus Publishing. 
Davis, M. H. (1983), 'Measuring Individual Differences in Empathy: Evidence for a Multidimensional Approach', Journal of Personality \& Social Psychology, 44(1): 113126.

Davis, M. H. (2005), 'A "Constituent" Approach to the Study of Perspective Taking: What are its Fundamental Elements?', in B. F. Malle and S. D. Hodges (eds.), Other Minds: How Humans Bridge the Divide Between Self and Others, New York: The Guilford Press, pp. 44-55.

Davis, M. H. and L. A. Kraus (1991), 'Dispositional Empathy and Social Relationships', in W. H. Jones and D. Perlman (eds.), Advances in Personal Relationships (Vol. 3), Greenwich, CT: JAI Press, pp. 75-115.

Dew, N., S. Sarasvathy, S. Read, and R. Wiltbank (2009), 'Affordable Loss: Behavioral Economic Aspects of the Plunge Decision', Strategic Entrepreneurship Journal, 3(2): $105-126$.

Dimov, D. (2007), 'Beyond the Single-person, Single-insight Attribution in Understanding Entrepreneurial Opportunities', Entrepreneurship: Theory and Practice, 31(5): 713731.

Dimov, D. (2011), 'Grappling with the Unbearable Elusiveness of Entrepreneurial Opportunities', Entrepreneurship: Theory and Practice, 35(1): 57-81.

Duan, C. and C. E. Hill (1996), 'The Current State of Empathy Research', Journal of Counseling Psychology, 43(3): 261.

Dutton, J. E., M. C. Worline, P. J. Frost, and J. Lilius (2006), 'Explaining Compassion Organizing', Administrative Science Quarterly, 51(1): 59-96.

Dymond, R. F. (1949), 'A Scale for the Measurement of Empathic Ability', Journal of Consulting Psychology, 13(2): 127-133.

Eckhardt, J. T. and S. A. Shane (2003), 'Opportunities and Entrepreneurship', Journal of Management, 29(3): 333-349.

Emirbayer, M. and A. Mische (1998), 'What Is Agency?', American Journal of Sociology, 103(4): 962-1023.

Epley, N., E. M. Caruso, and M. H. Bazerman (2006), 'When Perspective Taking Increases Taking: Reactive Egoism in Social Interaction', Journal of Personality \& Social Psychology, 91(5): 872-889.

Foss, N. J. and G. Garzarelli (2007), 'Institutions as Knowledge Capital: Ludwig M. Lachmann's Interpretive Institutionalism', Cambridge Journal of Economics, 31(5): 789-804.

Foss, N. J. and P. G. Klein (2008), 'Entrepreneurship, Subjectivism, and the Resource-based View: Toward a New Synthesis', Strategic Entrepreneurship Journal, 2(1): 73-94.

Foss, N. J. and P. G. Klein (2012), Organizing Entrepreneurial Judgment: A New Approach to the Firm, Cambridge, UK: Cambridge University Press.

Frost, P. J., J. E. Dutton, M. C. Worline, and A. Wilson (2000), Two Narratives of Compassion in Organizations, London: Sage.

Galinsky, A. D., W. W. Maddux, D. Gilin, and J. B. White (2008), 'Why it Pays to Get Inside the Head of Your Opponent: The Differential Effects of Perspective Taking and Empathy in Negotiations', Psychological Science, 19(4): 378-384.

Goleman, D. (1995), Emotional Intelligence, New York: Bantam Books.

Goody, E. E. (ed.) (1995), Social Intelligence and Interaction: Expressions and Implications of the Social Bias in Human Intelligence, New York: Cambridge University Press.

Granovetter, M. (1985), 'Economic Action and Social Structure: The Problem of Embeddedness', American Journal of Sociology, 91(3): 481-510. 
Grant, A. M. and J. W. Berry (2011), 'The Necessity of Others is the Mother of Invention: Intrinsic and Prosocial Motivations, Perspective Taking, and Creativity', Academy of Management Journal, 54(1): 73-96.

Gregoire, D. A., P. S. Barr, and D. A. Shepherd (2010a), 'Cognitive Processes of Opportunity Recognition: The Role of Structural Alignment', Organization Science, 21(2): 413431.

Gregoire, D. A., D. A. Shepherd, and L. S. Lambert (2010b), 'Measuring Opportunityrecognition Beliefs Illustrating and Validating an Experimental Approach', Organizational Research Methods, 13(1): 114-145.

Hammond, K. R. (1996), Human Judgment and Social Policy: Irreducible Uncertainty, Inevitable Error, Unavoidable Injustice, Oxford, UK: Oxford University Press.

Hastie, R. (2001), 'Problems for Judgment and Decision Making', Annual Review of Psychology, 52(1): 653-683.

Hastie, R. and K. Rasinski (1987), 'The Concept of Accuracy in Social Judgment', in D. BarTal and A. Kruglanski (eds.), The Social Psychology of Knowledge, Cambridge, UK: Cambridge University Press, pp. 193-208.

Hayek, F. A. (1937), 'Economics and Knowledge', Economica, 4(13): 33-54.

High, J. (1982), 'Alertness and Judgment: Comment on Kirzner', in I. M. Kirzner (ed.), Method, Process, and Austrian Economics, Washington, DC: Heath and Company, pp. 161-168.

Hogarth, R. M. (1981), 'Beyond Discrete Biases: Functional and Dysfunctional Aspects of Judgmental Heuristics', Psychological Bulletin, 90(2): 197-217.

Holcombe, R. G. (2003a), 'Progress and Entrepreneurship', Quarterly Journal of Austrian Economics, 6(3): 3-26.

Holcombe, R. G. (2003b), 'The Origins of Entrepreneurial Opportunities', The Review of Austrian Economics, 16(1): 25-43.

Ickes, W. (1993), 'Empathic Accuracy', Journal of Personality, 61(4): 587-610.

Ickes, W. (ed.) (1997), Empathic Accuracy, New York: Guilford Press.

Ickes, W., L. Stinson, V. Bissonnette, and S. Garcia (1990), 'Naturalistic Social Cognition: Empathic Accuracy in Mixed-sex Dyads', Journal of Personality \& Social Psychology, 59(4): 730-742.

Johnson, S. (2010), Where Good Ideas Come From, New York: Penguin.

Jolls, C., C. R. Sunstein, and R. Thaler (1998), 'A Behavioral Approach to Law and Economics', Stanford Law Review, 1471-1450.

Kirzner, I. (1973), Competition and Entrepreneurship, Chicago: University of Chicago Press.

Kirzner, I. M. (1982), 'Uncertainty, Discovery, and Human Action: A Study of the Entrepreneurial Profile in the Misesian System', in I. M. Kirzner (ed.), Method, Process, and Austrian Economics, Washington, DC: Heath and Company, pp. 139159.

Kirzner, I. M. (1997), 'Entrepreneurial Discovery and the Competitive Market Process: An Austrian Approach', Journal of Economic Literature, 35(March): 60-85.

Klein, P. G. (2008), 'Opportunity Discovery, Entrepreneurial Action, and Economic Organization', Strategic Entrepreneurship Journal, 2(3): 175-190.

Knight, F. H. (1921), Risk, Uncertainty and Profit, Washington, DC: BeardBooks.

Koen, P., G. Ajamian, R. Burkart, A. Clamen, J. Davidson, R. D’Amore, C. Elkins, K. Herald, M. Incorvia, A. Johnson, R. Karol, R. Seibert, A. Slavejkov, and K. Wagner (2001), 'Providing Clarity and a Common Language to the "Fuzzy Front End"', ResearchTechnology Management, 44(2): 46-55. 
Koppl, R. G. (1998), 'Lachmann on the Subjectivism of Active Minds', in R. Koppl and G. Mongiovi (eds.), Subjectivism and Economic Analysis: Essays in Memory of Ludwig M. Lachmann, London: Routledge, pp. 61-79.

Lachmann, L. (1971), The Legacy of Max Weber, Berkeley, CA: Glendessary.

Lachmann, L. (1976), 'From Mises to Shackle: An Essay on Austrian Economics and the Kaleidic Society', Journal of Economic Literature, 14(1): 54-62.

Lachmann, L. (1977), Capital, Expectations, and the Market Process, Kansas City, MO: Sheed, Andrews, and McMeel.

Lewin, K. (1999), 'Intention, Will and Need', in M. Gold (ed.), The Complete Social Scientist, Washington, DC: American Psychological Association, pp. 83-116.

Lewis, P. and J. Runde (2007), 'Subjectivism, Social Structure and the Possibility of SocioEconomic Order: The Case of Ludwig Lachmann', Journal of Economic Behavior \& Organization, 62(2): 167-186.

Lilius, J. M., M. C. Worline, S. Maitlis, J. Kanov, J. E. Dutton, and P. Frost (2008), 'The Contours and Consequences of Compassion at Work', Journal of Organizational Behavior, 29(2): 193-218.

Locke, E. A. and G. P. Latham (1990), A Theory of Goal Setting \& Task Performance, Englewood Cliffs, NJ: Prentice-Hall, Inc.

Luce, R. D. and H. Raiffa (1957), Games and Decisions: Introduction and Critical Survey, New York: Wiley \& Sons.

March, J. G. (1982), 'Theories of Choice and Making Decisions', Society, 20(1): 29-39.

March, J. G. and Z. Shapira (1992), 'Variable Risk Preferences and the Focus of Attention', Psychology Review, 99(1): 172-183.

McBane, D. A. (1995), 'Empathy and the Salesperson: A Multidimensional Perspective', Psychology and Marketing, 12(4): 349-370.

McMullen, J. S. (2010), 'Perspective Taking and the Heterogeneity of the Entrepreneurial Imagination', in R. Koppl, S. Horwitz, and P. Desrochers (eds.), Advances in Austrian Economics, Bingley, UK: Emerald Group Publishing Limited, pp. 113-144.

McMullen, J. S. (2011), 'Delineating the Domain of Development Entrepreneurship: A Market-based Approach to Facilitating Inclusive Economic Growth', Entrepreneurship Theory and Practice, 35(1): 185-215.

McMullen, J. S. and D. Dimov (2013), 'Time and the Entrepreneurial Journey: The Problems and Promise of Studying Entrepreneurship as a Process', Journal of Management Studies, 50(8): 1481-1512.

McMullen, J. S., L. Plummer, and Z. Acs (2007), 'What is an Entrepreneurial Opportunity?', Small Business Economics, 28(4): 273-283.

McMullen, J. S. and D. A. Shepherd (2006), 'Entrepreneurial Action and the Role of Uncertainty in the Theory of the Entrepreneur', Academy of Management Review, 31(1): 132-152.

McMullen, J. S., M. Wood, and L. Palich (2014), 'Entrepreneurial Cognition and Social Cognitive Neuroscience', in J. R. Mitchell, B. Randolph-Seng, and R. K. Mitchell (eds.), Handbook of Entrepreneurial Cognition, Northampton, MA: Edward Elgar, Forthcoming.

Menger, C. (1950), Principles of Economics, Glencoe, IL: Free Press.

Miller, T. L., M. G. Grimes, J. S. McMullen, and T. J. Vogus (2012), 'Venturing for Others with Heart and Head: How Compassion Encourages Social Entrepreneurship', Academy of Management Review, 37(4): 616-640.

Mises, L. V. (1949), Human Action (4th Rev. Ed.), San Francisco, CA: Fox \& Wilkes. 
Mullins, J. W. and D. Forlani (2005), 'Missing the Boat or Sinking the Boat: A Study of New Venture Decision Making', Journal of Business Venturing, 20(1): 47-69.

Newell, A. and H. A. Simon (1972), Human Problem Solving, Englewood Cliffs, NJ: PrenticeHall.

Oudshoorn, N., E. Rommes, and M. Stienstra (2004), 'Configuring the User as Everybody: Gender and Design Cultures in Information and Communication Technologies', Science, Technology, \& Human Values, 29(1): 30-63 (Winter).

Parker, S. K. and C. M. Axtell (2001), 'Seeing Another Viewpoint: Antecedents and Outcomes of Employee Perspective Taking', Academy of Management Journal, 44(5): 10851100 .

Piaget, J. and B. Inhelder (1956), The Child's Conception of Space, London: Routledge \& Kegan Paul.

Ray, M. (2004), The Highest Goal, San Francisco: Berrett-Koehler Publishers, Inc.

Rogers, E. M. (1995), Diffusion of Innovations (4th ed.), New York: The Free Press.

Ruby, P. and J. Decety (2001), 'Effect of Subjective Perspective Taking During Simulation of Action: A PET Investigation of Agency', Nature Neuroscience, 4(5): 546550.

Ruby, P. and J. Decety (2003), 'What You Believe Versus What You Think They Believe: A Neuroimaging Study of Conceptual Perspective-taking', European Journal of Neuroscience, 17(11): 2475-2480.

Ruby, P. and J. Decety (2004), 'How Would You Feel Versus How Do You Think She Would Feel? A Neuroimaging Study of Perspective-taking with Social Emotions', Journal of Cognitive Neuroscience, 16(6): 988-999.

Sarasvathy, S. D. (2001), 'Causation and Effectuation: Toward a Theoretical Shift from Economic Inevitability to Entrepreneurial Contingency', Academy of Management Review, 26(2): 243-263.

Sarasvathy, S. D. and N. Dew (2005), 'New Market Creation through Transformation', Journal of Evolutionary Economics, 15(5): 533-565.

Sarasvathy, S. D. and N. Dew (2013), 'Without Judgment: An Empirically-based Entrepreneurial Theory of the Firm', Review of Austrian Economics, 1-20, doi:10.1007/s11138-011-0170-4, 26(3): 277-296.

Sarasvathy, S. D., N. Dew, S. R. Velamuri, and S. Venkataraman (2003), 'Three Views of Entrepreneurial Opportunity', in Z. J. Acs and D. B. Audretsch (eds.), Handbook of Entrepreneurship Research: An Interdisciplinary Survey and Introduction, Riverside, CA: Springer, pp. 141-160.

Sautet, F. (2000), An Entrepreneurial Theory of the Firm, London: Routledge.

Schumpeter, J. A. (1934), The Theory of Economic Development: An Inquiry into Profits, Capital, Credit, Interest, and the Business Cycle, New Brunswick: Transaction Publishers.

Seely Brown, J. and P. Duguid (1992), 'Enacting Design for the Workplace', in P. S. Adler and T. A. Winograd (eds.), Usability: Turning Technologies into Tools, Oxford: Oxford University Press, pp. 164-197.

Sen, A. (1999), 'The Possibility of Social Choice', American Economic Review, 89(3): 349_ 378.

Shackle, G. L. S. (1979), Imagination and the Nature of Choice, Edinburgh, Scotland: Edinburgh University Press.

Shane, S. (2000), 'Prior Knowledge and the Discovery of Entrepreneurial Opportunities', Organization Science, 11(4): 448-469. 
Shane, S. (2011), 'Reflections on the 2010 AMR Decade Award: Delivering on the Promise of Entrepreneurship as a Field of Research', Academy of Management Review, 37(1): $10-20$.

Shane, S. and S. Venkataraman (2000), 'The Promise of Entrepreneurship as a Field of Research', Academy of Management Review, 25(1): 217-226.

Shapira, Z. (1997), Organizational Decision Making, Cambridge, UK: Cambridge University Press.

Shepherd, D. A., J. M. Haynie, and J. S. McMullen (2012), 'Confirmatory Search as a Useful Heuristic? Testing the Veracity of Entrepreneurial Conjectures', Journal of Business Venturing, 27(6): 637-651.

Shepherd, D. A., J. S. McMullen, and P. D. Jennings (2007), 'The Formation of Opportunity Beliefs: Overcoming Ignorance and Reducing Doubt', Strategic Entrepreneurship Journal, 1(1-2): 75-95.

Smith, K. and D. DiGregorio (2002), 'Bisociation, Discovery, and the Role of Entrepreneurial Action', in M. Hitt, R. D. Ireland, S. M. Camp, D. Sexton, R. D. Nixon, and C. E. Lucier (eds.), Strategic Entrepreneurship: Creating a New Mindset, Malden, MA: Blackwell, pp. 129-150.

Smith, P. G. and D. G. Reinertsen (1997), Developing Products in Half the Time, New York: Van Nostrand Reinhold.

Stieber, J. and P. Primeaux (1991), 'Economic Efficiency: A Paradigm for Business Ethics', Journal of Business Ethics, 10(5): 335-339.

Thomke, S. and T. Fujimoto (2000), 'The Effect of "Front-loading” Problem Solving on Product Development Performance', Journal of Product Innovation Management, 17(2): 128-142.

Veryzer, R. W. (2003), 'Marketing and the Development of Innovative New Products', in L. V. Shavinina (ed.), The International Handbook of Innovation, Boston, MA: Elsevier, pp. $845-858$.

Webb, B. R. (1996), 'The Role of Users in Interactive Systems Design: When Computers are Theatre, Do We Want the Audience to Write the Script?', Behavior \& Information Technology, 15(2): 76-83.

Weick, K. E. (1995), Sensemaking in Organizations, Thousand Oaks, CA: Sage.

Weick, K. E., K. M. Sutcliffe, and D. Obstfeld (2005), 'Organizing and the Process of Sensemaking', Organization Science, 16(4): 409-421.

Witt, U. (1998a), 'Imagination and Leadership: The Neglected Dimension of an Evolutionary Theory of the Firm', Journal of Economic Behavior and Organization, 35(2): 161-177.

Witt, U. (1998b), 'Do Entrepreneurs Need Firms?', Review of Austrian Economics, 11(1): 99-109. 